\title{
The cellular fate of mutant rhodopsin: quality control, degradation and aggresome formation
}

\author{
Richard S. Saliba ${ }^{1}$, Peter M. G. Munro ${ }^{2}$, Philip J. Luthert ${ }^{1}$ and Michael E. Cheetham ${ }^{1, *}$ \\ ${ }^{1}$ Division of Pathology and ${ }^{2}$ Electron Microscopy, Institute of Ophthalmology, University College London, London, UK \\ *Author for correspondence (e-mail: michael.cheetham@ucl.ac.uk) \\ Accepted 1 May 2002 \\ Journal of Cell Science 115, 2907-2918 (2002) (C) The Company of Biologists Ltd
}

\begin{abstract}
Summary
Mutations in the photopigment rhodopsin are the major cause of autosomal dominant retinitis pigmentosa. The majority of mutations in rhodopsin lead to misfolding of the protein. Through the detailed examination of $\mathrm{P23H}$ and K296E mutant opsin processing in COS-7 cells, we have shown that the mutant protein does not accumulate in the Golgi, as previously thought, instead it forms aggregates that have many of the characteristic features of an aggresome. The aggregates form close to the centrosome and lead to the dispersal of the Golgi apparatus. Furthermore, these aggregates are ubiquitinated, recruit cellular chaperones and disrupt the intermediate filament network. Mutant opsin expression can disrupt the processing of normal opsin, as co-transfection revealed that the wild-type protein is recruited to mutant opsin aggregates. The degradation of mutant opsin is dependent on the proteasome machinery. Unlike the situation with $\triangle$ F508-CFTR, proteasome inhibition does not lead to a marked increase in aggresome formation but increases the retention of the protein within the $E R$, suggesting that the
\end{abstract}

proteasome is required for the efficient retrotranslocation of the mutant protein. Inhibition of N-linked glycosylation with tunicamycin leads to the selective retention of the mutant protein within the ER and increases the steady state level of mutant opsin. Glycosylation, however, has no influence on the biogenesis and targeting of wild-type opsin in cultured cells. This demonstrates that $\mathrm{N}$-linked glycosylation is required for ER-associated degradation of the mutant protein but is not essential for the quality control of opsin folding. The addition of 9-cis-retinal to the media increased the amount of $\mathrm{P} 23 \mathrm{H}$, but not $\mathrm{K} 296 \mathrm{E}$, that was soluble and reached the plasma membrane. These data show that rhodopsin autosomal dominant retinitis pigmentosa is similar to many other neurodegenerative diseases in which the formation of intracellular protein aggregates is central to disease pathogenesis, and they suggest a mechanism for disease dominance.

Key words: Rhodopsin, Aggresome, Proteasome, Chaperone, Glycosylation, Retinitis pigmentosa

\section{Introduction}

Retinitis pigmentosa (RP) is the most common cause of inherited retinal degeneration and is clinically characterised by night blindness and the loss of peripheral vision followed by the loss of central vision. Mutations in the rod visual pigment, rhodopsin were first described in 1990 (Dryja et al., 1990) and are now recognised as the most common cause of retinitis pigmentosa (RP), accounting for approximately $15 \%$ of all inherited retinal degenerations (Chapple et al., 2001) (OMIM 180380: http://www.ncbi.nlm.nih.gov/entrez/dispomim.cgi?id= 180380). Over 100 mutations in rhodopsin have now been described (RetNet: http://www.sph.uth.tmc.edu/RetNet/ home.htm). Although some of these mutations cause recessive RP and congenital stationary night blindness (CSNB), the vast majority are associated with autosomal dominant RP (ADRP).

Several of these mutations have been studied in detail at the cellular and transgenic animal level. These studies suggest that rhodopsin mutations can be divided into two major categories on the basis of the mechanisms of pathogenesis. Mutations at the C-terminus of rhodopsin interfere with the normal targeting of the protein to the photoreceptor outer segment (Sung et al., 1991; Sung et al., 1994; Tam et al., 2000), whereas mutations in the transmembrane, intradiscal or cytoplasmic domains result in the misfolding of the protein (Kaushal and Khorana, 1994; Olsson et al., 1992; Roof et al., 1994; Sung et al., 1991;
Sung et al., 1993). The mechanisms by which these misfolded and misrouted proteins lead to photoreceptor death by apoptosis (Portera Cailliau et al., 1994), however, remain unidentified.

In transfected cells, rhodopsin with mutations in the transmembrane, intradiscal or cytoplasmic domains fails to translocate to the plasma membrane and accumulates within the cell, in what has been described as the ER and Golgi (Kaushal and Khorana, 1994; Sung et al., 1991; Sung et al., 1993). These mutant proteins trapped within the cell cannot form the visual pigment with 11-cis-retinal (Kaushal and Khorana, 1994; Sung et al., 1991; Sung et al., 1993) and are found in a complex with the ER-resident chaperones BiP and Grp94 (Anukanth and Khorana, 1994), supporting the notion that they are incorrectly folded. It appears, therefore, that these mutations result in a protein that cannot translocate to the plasma membrane in cultured cells or to the outer segment in photoreceptors because it is misfolded.

The failure of rhodopsin to translocate to the outer segment per se does not appear to be enough to cause retinitis pigmentosa, as heterozygous rhodopsin knockout mice display little photoreceptor cell death (Humphries et al., 1997). Rather, it would appear that misfolded rhodopsin acquires a 'gain of function' that leads to cell death. Recent insights into the fate of misfolded proteins in mammalian cells has suggested that 
there may be a common cellular response to unfolded proteins, the formation of a specialised structure, the aggresome (Kopito, 2000). Aggresomes are thought to result from a saturation of the normal proteolytic machinery by misfolded proteins and accumulate as ubiquitinated inclusions near the centrosome. Other characteristic features of aggresomes are the disruption of the Golgi and intermediate filament networks and the recruitment of cellular chaperones (Garcia-Mata et al., 1999; Johnston et al., 1998; Kopito, 2000).

The presence of ubiquitinated, proteinacious inclusions within neurones is associated with many forms of neurodegeneration, including Amyotrophic Lateral Sclerosis, Alzheimer's disease, Parkinson's disease and several hereditary diseases caused by expansions of polyglutamine repeats (e.g., Huntington's disease and the spinocerebellar ataxias) (Alves-Rodrigues et al., 1998; Kaytor and Warren, 1999; Sherman and Goldberg, 2001). Studies of the inclusions formed in some of these diseases and the pathogenetic basis of mutations that lead to some neurodegenerations have suggested that they share features with aggresomes (Johnston et al., 2000; Waelter et al., 2001). Indeed, a recent study of P23H mutant opsin expression in cell culture has shown that mutant opsin aggregates colocalise, but do not co-aggregate, with other proteins that form aggresomes, such as $\triangle$ F508 CFTR and TCR $\alpha$ subunits (Rajan et al., 2001). In this study, we have further investigated the fate of mutant rhodopsin in vitro, identifying the formation of ubiquitinated mutant opsin aggresomes and delineating mechanisms of mutant opsin quality control and degradation. The relevance to RP is further highlighted by the observation that mutant opsin can recruit the normal protein to aggresomes.

\section{Materials and Methods}

\section{Reagents}

DAPI for nuclear staining, tunicamycin (containing homologues A,B,C, and D), 9-cis-retinal and Protease Inhibitor Cocktail in DMSO for mammalian cell extracts were purchased from Sigma. The proteasome inhibitor MG-132 (Z-leu-leu-leu CHO) was purchased from Biomol Research Labs. Lipofectamine and Plus reagent were from Life Technologies. PNGase $\mathrm{F}$ and Endo $\mathrm{H}$ were from NEB. The primary antibodies used were mAb 1D4 to rhodopsin, which was a gift from R. Molday (University of British Columbia, Canada) and subsequently purchased from the National Cell Culture Centre; anti$\beta$-COP (clone maD) and anti-Hsc70 (clone BRM22), which were from Sigma; anti-Grp78 (BiP), which was from Santa Cruz Biotech; rabbit polyclonal anti-calnexin, which was from StressGen Biotechnologies; mouse monoclonal to vimentin from Dako Ltd; antiERGIC-53, which was a gift from H. P. Hauri (Basel). The secondary antibodies used were Goat anti-mouse Cy3 (Amersham Pharmacia Biotech); donkey anti-rabbit $\mathrm{Cy} 3$ and donkey anti-goat Cy3, both of which were from Jackson Immuno Research Laboratories; goat antimouse antibodies conjugated to horseradish peroxidase were from Pierce. The $\triangle$ F508 CFTR-GFP and c-myc-ubiquitin plasmids (Ward et al., 1995) were gifts from R. R. Kopito (Stanford). Bovine WT opsin and K296E opsin in pMT3 were gifts from D. Oprian (Brandeis). $\mathrm{P} 23 \mathrm{H}$ opsin in vector pMT3 was made by PCR-mediated site-directed mutagenesis using the WT in pMT3 as a template. Briefly, the following primer combinations were used: PCR reaction (i) rhodopsin forward primer 5' GGATCCGAATTCCACCATGAACGGTACCGAA 3', P23H reverse primer: 5' GCCTCGAAGTGGCTGCGCACCAC 3'; PCR reaction (ii) $\mathrm{P} 23 \mathrm{H}$ site forward primer $5^{\prime}$ GCAGCCACTTCGAGGCTCCGCAG $3^{\prime}$ and rhodopsin reverse primer 5' GCGGCCGCTTAGGCAGGCGCCACTTG 3'. The reaction products from (i) and (ii) were gel purified and used as a template in the final PCR reaction, which was amplified using rhodopsin forward primer and reverse rhodospin primer to generate the full-length $\mathrm{P} 23 \mathrm{H}$ rhodopsin gene. This was cloned into pGEM-T, digested with EcoRI and NotI and cloned into pMT3. WT, P23H and K296E opsin were cloned in frame with GFP into the BamHI/AgeI sites of pEGFP-N1 following PCR mutagenesis to remove the stop codon and include restriction sites, such that the GFP sequence was fused to the Ctermini of the opsin, following a similar methodology to an experiment described previously (Chapple et al., 2000). All construct sequences were confirmed by sequencing.

\section{Cell culture}

COS-7 cells were grown in DMEM/F12 with Glutamax-I+10\% heat inactivated FBS and $50 \mu \mathrm{g} / \mathrm{ml}$ gentamicin with an atmosphere of $5 \%$ $\mathrm{CO}_{2}$ at $37^{\circ} \mathrm{C}$. 24 hours after seeding glass eight-well chamber slides with $2 \times 10^{4}$ cells per well, the cells were transfected with $0.2 \mu \mathrm{g}$ DNA per well with $2 \mu \mathrm{l}$ of plus reagent and $1 \mu \mathrm{l}$ of lipofectamine according to the manufacturers instructions. For $35 \mathrm{~mm}$ dishes, the transfection mix was scaled up and cells were transfected 24 hours after seeding with $10^{6} \mathrm{COS}-7$ cells. For Golgi disruption experiments, brefeldin A (BFA) was added to the cells to a final concentration of $20 \mu \mathrm{g} / \mathrm{ml}$ for 15 minutes prior to fixation. For proteasome inhibition, cells were treated with MG-132 at $5 \mu \mathrm{M}$ for the indicated time and a parallel transfection of $\Delta$ F508 CFTR-GFP was used as a positive control for aggresome formation via proteasome inhibition. N-linked glycosylation was inhibited by the addition of tunicamycin to a final concentration of $0.8 \mu \mathrm{g} / \mathrm{ml}$ for the indicated treatment time; the efficiency of inhibition was confirmed by PNGase F treatment of samples. The incidence of aggresome formation was estimated by scoring 400 transfected cells from four separate experiments for the presence of aggresomes by an observer that was blind to the cell transfection status.

\section{Immunofluorescence}

The following fixation conditions were used for each antibody: for vimentin, Hsc70, $\beta$-COP and c-myc ubiquitin staining, COS-7 cells were fixed in $100 \%$ methanol at $-20^{\circ} \mathrm{C}$ for 6 minutes then washed twice in PBS; for BiP (Grp78) staining, cells were fixed in $3.7 \%$ formaldehyde in PBS for 20 minutes then washed three times in PBS for 5 minutes then permeabilised in $0.05 \%$ Triton X-100 for 5 minutes followed by two 5 minute washes in PBS. For calnexin staining, cells were fixed in $3 \%$ formaldehyde $/ 0.1 \%$ glutaraldehyde in $0.08 \mathrm{M}$ sodium cacodylate-HCl buffer, $\mathrm{pH} 7.4$ for 20 minutes followed by two 5 minute washes in $\mathrm{PBS}$ and one 5 minute wash in $50 \mathrm{mM} \mathrm{NH} 4 \mathrm{Cl}$ in PBS, followed by one rinse in PBS. Cells were permeabilised in $0.1 \%$ Triton X-100 and $0.05 \%$ SDS for 4 minutes followed by three 5 minute washes in PBS. Following fixation and permeabilisation, cells were blocked for 1 hour at $22^{\circ} \mathrm{C}$ with $10 \%$ appropriate normal serum, prior to incubation with antibodies. The primary antibodies were incubated for 1 hour at $22^{\circ} \mathrm{C}$, followed by three 5 minute washes in PBS, followed by a 1 hour incubation at $22^{\circ} \mathrm{C}$ with conjugated secondary antibodies and then washed with four washes for five minutes in PBS; DAPI was used at 1:5000 in PBS for 5 minutes in the third wash. The titres of antibodies used were: mouse anti- $\beta$-COP 1:50 dilution in PBS+10\% normal goat serum (NGS) followed by goat anti-mouse Cy3 1:500 in PBS+10\% NGS; mouse anti-vimentin 1:10 dilution in PBS $+10 \%$ NGS followed by goat anti-mouse Cy3 1:500 in PBS+10\% NGS; mouse anti-Hsc70(BRM22) 1:50 dilution in PBS+10\% NGS followed by goat anti-mouse Cy3 1:200 in PBS+10\% NGS; anti-c-myc hybridoma supernatant, clone 9E10, was used neat followed by goat anti-mouse Cy3 1:500 in PBS+10\% NGS; ERGIC53 1:1000 dilution of mouse ascites in PBS+10\% NGS followed by goat anti-mouse Cy3 1:500 in PBS+10\% NGS; rabbit anti-calnexin 
1:100 in PBS+10\% normal donkey serum (NDS) followed by donkey anti-rabbit Cy3 1:200 in PBS+10\% NDS; goat anti-BiP 1:40 in PBS $+10 \%$ NDS followed by donkey anti-goat Cy3 1:200 in PBS $+10 \%$ NDS. For dual labelling, opsin was visualised with $\mathrm{mAb}$ 1D4 conjugated to FITC, at a concentration of $2.5 \mu \mathrm{g} / \mathrm{ml}$ in PBS+10\% normal mouse serum and added after primary and secondary antibodies had bound and after three 5 minute washes in PBS. Immunofluorescence was visualised with a Zeiss LSM 510 laser scanning confocal microscope. The following excitation/emission conditions were used in separate channels with either the $\times 40$ or $\times 63$ oil immersion objective: DAPI 364/475-525 nm; FITC/GFP 488/505$530 \mathrm{~nm}$; Cy3 543/560 nm.

\section{Electron microscopy}

Cells were fixed overnight in Karnovsky's fixative (3\% glutaraldehyde, $1 \%$ paraformaldehyde in $0.08 \mathrm{M}$ sodium cacodylate$\mathrm{HCl}$ buffer, $\mathrm{pH}$ 7.4) then rinsed three times in PBS and incubated in a $1 \%$ aqueous osmium tetroxide solution for 1 hour at room temperature. Following three rinses in distilled water, cells were dehydrated by 10 minute immersions in $50 \%, 70 \%, 90 \%$ and $4 \times 100 \%$ ethanol. Finally, the wells containing dehydrated cells were filled with araldite resin and placed in a $60^{\circ} \mathrm{C}$ oven to harden overnight. Sections for examination by transmission electron microscopy were cut using a Leica ultracut $\mathrm{S}$ microtome and diamond knife, mounted on copper grids and contrasted with lead citrate. Images were viewed using a JEOL 1010 TEM operating at $80 \mathrm{kV}$ and photographs recorded onto Kodak electron image film.

\section{Preparation of cell extracts}

24 hours after transfection, cells were treated with $5 \mu \mathrm{M}$ MG-132 for 16 hours or $0.8 \mu \mathrm{g} / \mathrm{ml}$ Tunicamycin for 16 hours in DMEM/F12 with Glutamax-I+10\% FBS without antibiotics. Cells were washed twice in $4^{\circ} \mathrm{C}$ PBS and incubated in $290 \mu \mathrm{l}$ PBS/1\% n-Dodecyl- $\beta$-D-Maltoside plus $10 \mu \mathrm{l}$ of protease inhibitor cocktail and $166 \mu \mathrm{M}$ MG-132 for 30 minutes on ice. Cell lysates were transferred to $1.5 \mathrm{ml}$ microcentifuge tubes on ice and homogenised by passage through a $23 \mathrm{G}$ needle five times. $200 \mu \mathrm{l}$ of cell lysate was centrifuged at $17,500 \mathrm{~g}$ for 15 minutes at $4^{\circ} \mathrm{C}$. Pellets were solublised in $50 \mu \mathrm{l} 10 \mathrm{mM}$ Tris. $\mathrm{HCl} \mathrm{pH} \mathrm{7.5,1 \%}$ SDS $+2 \mu$ protease inhibitor cocktail for 5 minutes at $22^{\circ} \mathrm{C} .150 \mu \mathrm{l}$ of RIPA buffer (50 mM Tris-HCl pH 8, $150 \mathrm{mM} \mathrm{NaCl}, 1 \mathrm{mM}$ EDTA, $1 \%$ NP-40, $0.1 \%$ SDS, $0.05 \%$ sodium deoxycholate) was added, and the pellets were then sonicated for three 5 second bursts. For SDS PAGE, an equal volume of $2 \times$ modified Laemmli sample buffer (1Xsample buffer, $0.125 \mathrm{M}$ Tris-HCl, pH 6.8, 5\% SDS, $15 \%$ glycerol, $10 \% 2$ mercaptoethanol $0.012 \%$ bromophenol blue) was added to the soluble and insoluble fraction. For immunoblotting, cell fractions were normalised for total protein and separated by $10 \%$ SDS-PAGE and electroblotted onto nitrocellulose. For immunodetection of opsin, mAb 1D4 was used at a concentration of $0.5 \mu \mathrm{g} / \mathrm{ml}$ and goat anti-mouse HRP (Pierce) was used at 1:50,000 in PBS+5\% Marvel (Premier Brands), $0.1 \%$ Tween-20. The chemiluminescent detection reagent ECL Plus (Amersham Pharmacia Biotech) was used to detect immobilised antigens according to the manufacturer's instructions. The electrophoretic mobility of different opsin glycoforms was determined empirically using PNGase F and Endo $\mathrm{H} ; 15 \mu \mathrm{g}$ protein was digested with PNGase F (1500 units) or Endo H (1500 units) for 2 hours at $37^{\circ} \mathrm{C}$ in $1 \times \mathrm{G} 7$ (PNGase) or $1 \times \mathrm{G} 5$ (Endo $\mathrm{H}$ ) buffer (NEB) before resolving by SDS-PAGE as described above.

\section{Results}

Mutant rhodopsin does not accumulate in the Golgi

Several studies have suggested that mutant opsins that cannot fold correctly are retained within the ER and Golgi (Kaushal and Khorana, 1994; Sung et al., 1991; Sung et al., 1993). To investigate this further, we studied the fate of wild-type and mutant P23H and K296E opsin with and without a C-terminal green fluorescent protein (GFP) tag in COS-7 cells. COS-7 cells have been used extensively to study opsin expression. The localisation of the opsins was investigated by confocal immunofluorescence using the intrinsic GFP fluorescence and with opsin and Golgi protein antibody markers (Fig. 1). In the case of wild-type opsin, the majority of the protein is processed to the plasma membrane with some staining in the ER and Golgi network indicating the normal biogenesis of the protein (Fig. 1). By contrast, the mutant opsins $\mathrm{P} 23 \mathrm{H}$ (Fig. 1) and K296E (data not shown) are not processed to the plasma membrane but accumulate in the ER, and, in a significant proportion of cells, the protein accumulates in a juxtanuclear region that shows a partial colocalisation with the Golgi and intermediate compartment markers $\beta$-COP (Fig. 1) and ERGIC-53 (data not shown). However, the level of $\beta$-COP staining is greatly reduced in the cells that have mutant opsin aggregates (Fig. 1), suggesting that the Golgi is disrupted by the presence of the mutant protein. The addition of GFP to the C-terminus of the protein does not alter the cellular fate of the opsin (Fig. 1) but does appear to increase the rate of inclusion formation for both the wild-type and mutant proteins, such that a higher proportion of cells possess the juxtanuclear aggregates (incidence of inclusion formation P23H-GFP>K296EGFP $>$ P23H $>$ K296E $>$ WT-GFP $>$ WT).

To confirm that the mutant protein was not present in the Golgi we used brefeldin A (BFA) to disrupt the Golgi apparatus. Treatment with BFA dispersed the Golgi in all the cells and dispersed the wild-type opsin trafficking through the Golgi but had no effect on the mutant opsin inclusion (Fig. 2). Treatment with BFA for periods up to 8 hours did not reduce the incidence of aggregate formation, suggesting that transport of opsin from the ER to Golgi is not required for the formation of these aggregates. Therefore, the mutant protein was not trapped within the Golgi and instead appeared to be associated with a distinct structure located close to the Golgi.

\section{Mutant opsin forms ubiquitinated aggresome-like structures}

As the mutant opsin appeared to form an intracellular inclusion that had some of the characteristics of an aggresome (Kopito, 2000), we investigated whether they shared other features with aggresomes. Cotransfection of P23H opsin (Fig. 3) or K296E opsin (data not shown) with c-myc-tagged ubiquitin resulted in the recruitment of ubiquitin to the opsin inclusions, suggesting that the structures are ubiquitinated. There was no association of ubiquitin with the wild-type protein, the ubiquitin retained its diffuse pan-cellular staining pattern and did not colocalise with the opsin at any stage of its biogenesis (data not shown). The presence of opsin inclusions also led to the disruption of the intermediate filament network as shown by vimentin staining (Fig. 3). Vimentin is relocalised from its normal distribution to a bright ring surrounding the inclusion, a feature seen in many aggresome-like structures (Kopito, 2000). Examination of the colocalisation of molecular chaperones with inclusions demonstrated that the cytoplasmic chaperone Hsc70 (of the Hsp70 family) is recruited to the inclusions. By contrast, the ER-resident $\mathrm{Hsp} 70, \mathrm{BiP}$, is predominantly 
Fig. 1. Mutant opsin accumulates in a structure close to the Golgi apparatus. The cellular localisations of opsin in transiently transfected COS-7 cells expressing WT opsin and WT opsin with a C-terminal GFP tag (WT-GFP) were compared with mutant opsin (P23H-opsin) and GFP-tagged mutant opsin (P23H-GFP) by confocal immunofluorescence. The intracellular opsin colocalised with the Golgi marker $\beta$-COP; however, in cells with mutant opsin inclusions, the $\beta$-COP staining is dispersed. Bar, $10 \mu \mathrm{m}$.
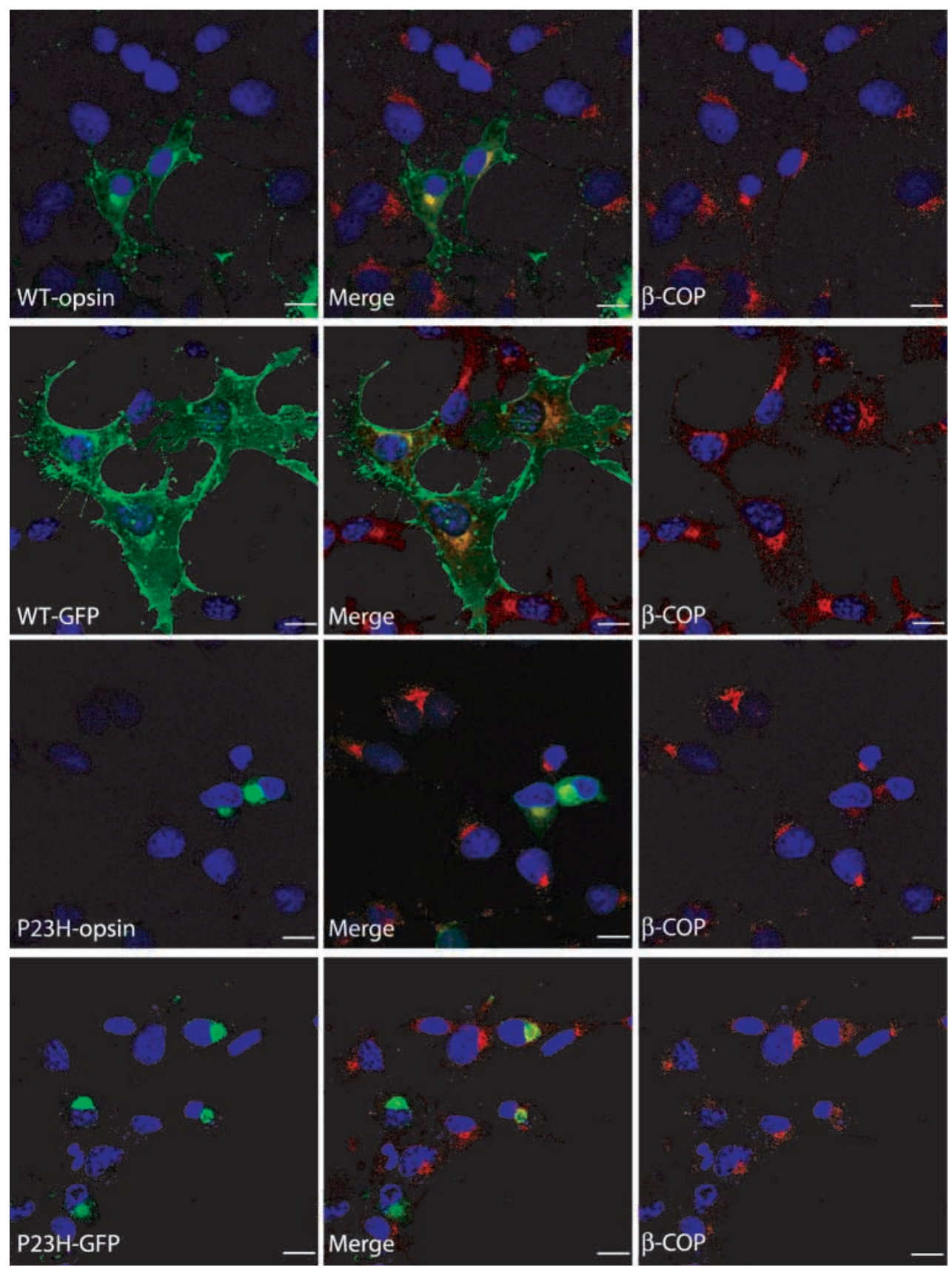

excluded from the inclusions but does occasionally localise at the periphery of the inclusion forming a ring around the inclusion (data not shown), a pattern that was also seen with other ER markers. Collectively, these data suggest that the mutant opsin inclusions are aggresomes.

\section{Ultrastructure of opsin aggresomes}

Electron microscopy of COS-7 cells containing mutant opsins confirmed the localisation of the aggregate close to the microtubule organising centre (MTOC) and the disruption of the Golgi and intermediate filament networks (Fig. 4). The juxtanuclear structures were also surrounded by mitochondria. These mutant opsin structures, therefore, display most of the ultrastructural hallmarks of aggresomes. The membrane content of the structures, however, was much higher than that observed in aggresomes (Heath et al., 2001; Johnston et al., 1998; Waelter et al., 2001) formed from other proteins, and in places the structure appears to be surrounded by membranes (arrowheads in Fig. 4). This may correspond to the 'ring' of ER staining that was observed in some cells and could reflect the highly hydrophobic nature of the opsin transmembrane domains acting to recruit lipid vesicles as well as cellular chaperones.

Co-expression of wild-type and mutant opsin results in recruitment of the normal protein to the mutant opsin aggresome

We investigated whether mutant opsin aggresome formation 
Fig. 2. Mutant opsin does not accumulate in the Golgi. Cells expressing WT (WT-GFP) and mutant (P23H-GFP) opsin tagged with GFP were treated with BFA $(20 \mu \mathrm{g} / \mathrm{ml}$ for 15 minutes prior to fixation). BFA dispersed the Golgi ( $\beta$-COP) and the WT-GFP opsin that was trafficking through the Golgi but did not disperse the P23H-GFP opsin from its juxtanuclear position. Bar, $10 \mu \mathrm{m}$.
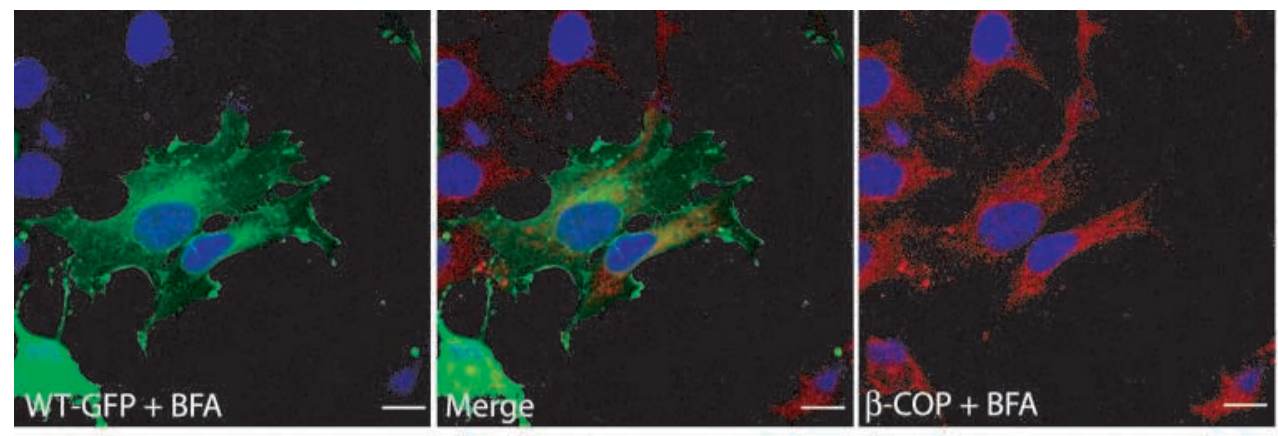

could influence the processing of the normal wild-type protein in cell culture. COS-7 cells were co-transfected with the wildtype protein tagged at its C-terminus with GFP and untagged wild-type or untagged $\mathrm{P} 23 \mathrm{H}$ mutant protein. To make a clearer distinction between normal trafficking through the Golgi and inclusion formation, the cells were treated with BFA prior to fixation and analysis of wild-type opsin-GFP localisation. Co-transfection of normal wild-type opsin-GFP with an excess of WT untagged opsin did not lead to an increase in inclusion formation above that seen with the GFP-tagged protein alone. By contrast, co-transfecting wild-type opsin-GFP with untagged $\mathrm{P} 23 \mathrm{H}$ opsin led to a significant increase in the incidence of wild-type opsin aggresomes (Fig. 5). In the presence of an excess of untagged $\mathrm{P} 23 \mathrm{H}$ opsin, the incidence of cells with aggresomes containing the WT opsin-GFP approached the level of aggresome formation seen with untagged $\mathrm{P} 23 \mathrm{H}$ opsin alone (between 35 and 50\% at 24

Fig. 3. Mutant opsin inclusions have the characteristics of an aggresome. Mutant opsin (P23H-GFP) colocalised with c-myctagged ubiquitin when co-tranfected in COS-7 cells. The P23H-GFP opsin inclusions led to the disruption of the intermediate filament network (Vimentin). The cytoplasmic chaperone Hsc70 was recruited to the $\mathrm{P} 23 \mathrm{H}-\mathrm{GFP}$ inclusions. Bar, $10 \mu \mathrm{m}$
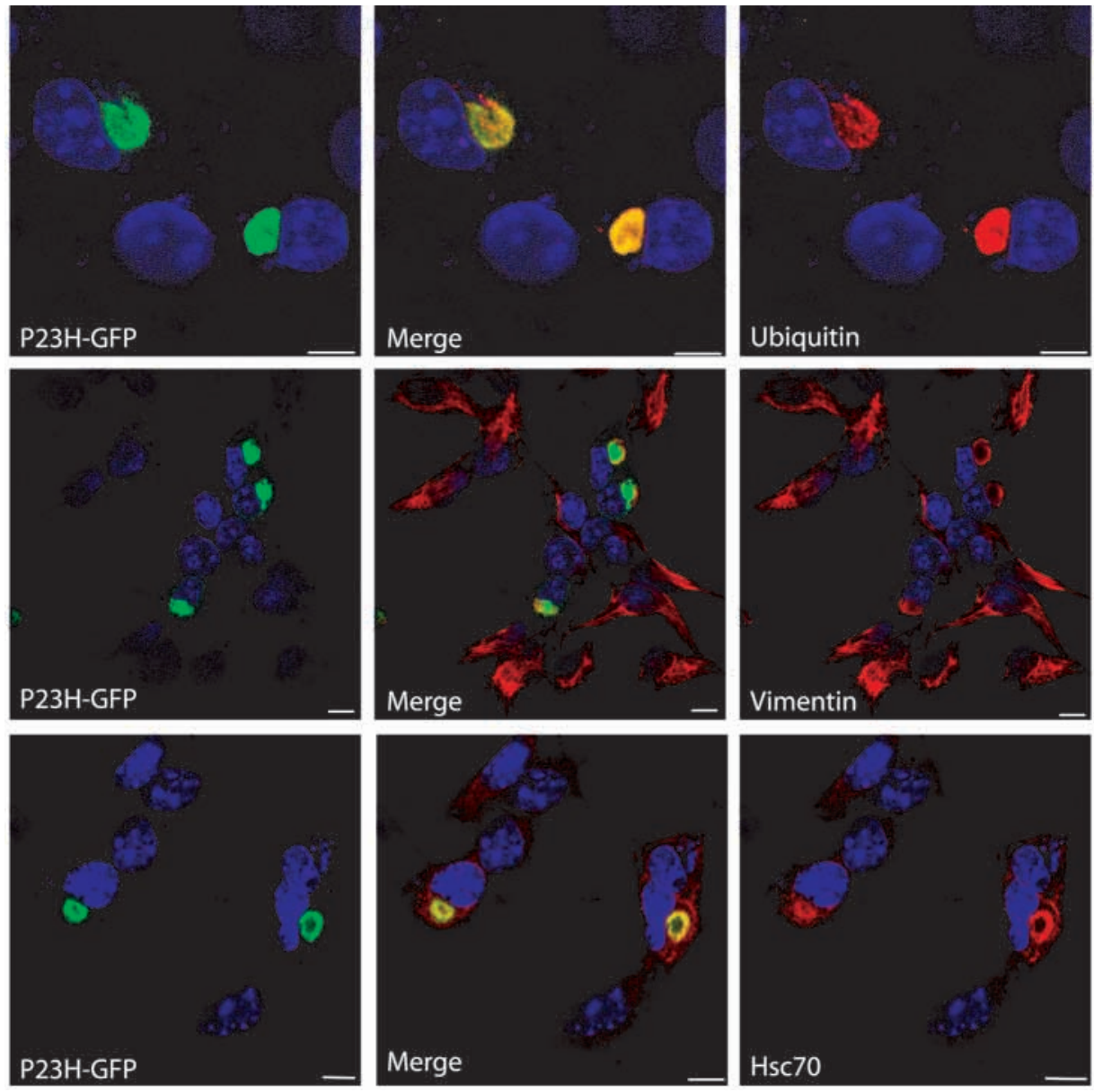
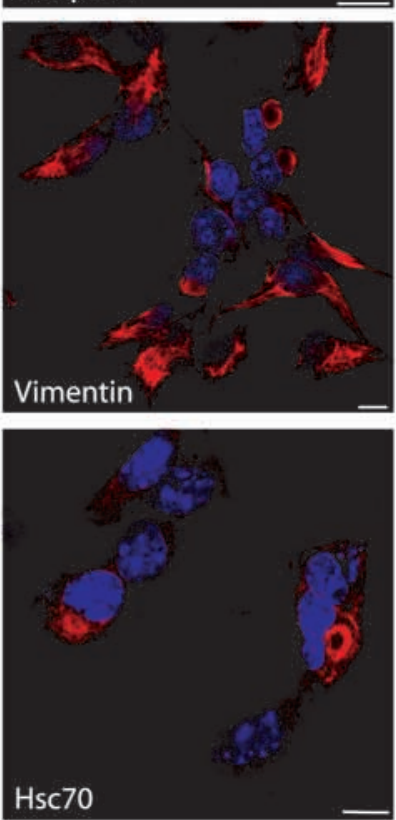
Fig. 4. Ultrastructure of opsin aggresomes. Electron micrograph of a COS-7 cell with a P23H-GFP mutant aggresome. (i) The aggresome (A) forms near the nucleus $(\mathrm{N})$ and centrosome $(\mathrm{C})$ and is surrounded by mitochondria (M). (ii) At higher magnification the intermediate filaments (IF) that surround the aggresome can be seen. (iii) The aggresome also has a high membrane content and in places appears to be surrounded by membrane (arrowheads). Bar, $1 \mu \mathrm{m}$.
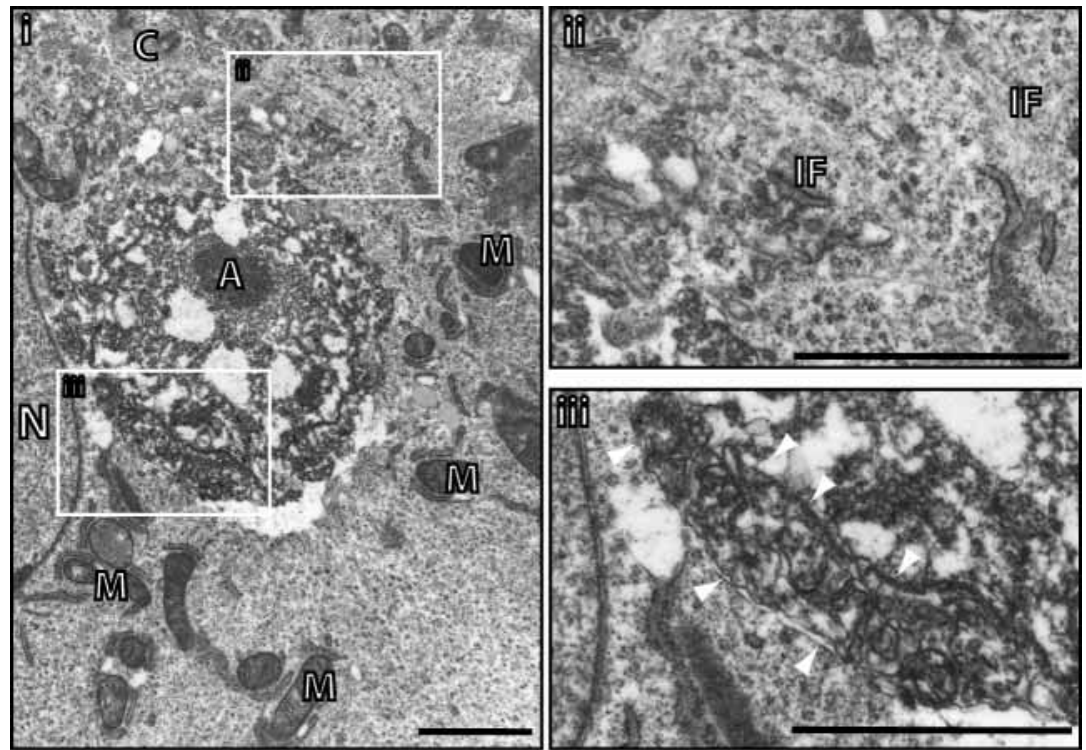

Degradation of mutant opsin is via the ubiquitinproteasome pathway and the proteasome is required for efficient retrotranslocation

As aggresome formation is generally enhanced by treatment with proteasome inhibitors, we examined the effect of the proteasome inhibitor MG-132 on opsin aggresome formation. In contrast to the expression of $\Delta$ F508-CFTR where proteasome inhibition leads to aggresome formation in 100\% of transfected cells (Johnston et al., 1998), treatment with MG-132 for 8 or 14 hours did not have a marked effect on the incidence of aggresome formation by $\mathrm{P} 23 \mathrm{H}, \mathrm{K} 296 \mathrm{E}$ or wild-type opsin as assessed by aggresome counts (data not shown). Morphologically, the most pronounced effect of proteasome inhibition was to increase the intensity of ER staining of mutant opsin as demonstrated by colocalisation with BiP (Fig. 6) and calnexin (data not shown). In untreated cells (Fig. 1 and Fig. 8, untreated), the level of mutant opsin staining in the ER was relatively weak compared with the staining of the aggregates. Following treatment with MG-132, there was little change in the pattern of wild-type opsin staining but a dramatic increase in the intensity of ER staining of the mutant opsins was observed in all cells (Fig. 6).

The increase in mutant opsin ER staining correlated with an

Fig. 5. Co-transfection of normal and mutant opsin leads to the recruitment of the normal protein to the mutant opsin aggresome. (A) GFP-tagged WT opsin in pEGFP was co-transfected with untagged WT opsin in pMT3 (WT-GFP/WT-opsin) at a vector ratio of 1:10. Cells showed no increase in aggresome formation compared with WT-GFP alone, whereas co-transfection of GFP-tagged WT opsin in pEGFP with untagged P23H opsin in pMT3 (WTGFP/P23H-opsin) at a vector ratio of 1:10 increased the percentage of WT opsin recruited to aggresomes, as judged by GFP fluorescence. Bar, $10 \mu \mathrm{m}$. (B) Quantification of co-transfection aggresome formation after 24 hours of opsin expression. The percentage of cells with WT-GFP fluorescence aggresomes was counted double blindly from four separate experiments (error bars \pm 2 s.d.). BFA ( $20 \mu \mathrm{g} / \mathrm{ml}$ for 15 minutes prior to fixation) was added to both experiments to reduce confusion over WT opsin in the secretory pathway. increase in the level of mutant protein, as judged by western blotting (Fig. 7). Following MG-132 treatment there was little change in the amount or the composition of the WT opsin in either the n-Dodecyl- $\beta$-D-Maltoside (DM) soluble or insoluble fractions. By contrast, the total amount of P23H and K296E opsin is dramatically increased after incubation with the proteasome inhibitor (Fig. 7). In the case of the $\mathrm{P} 23 \mathrm{H}$ mutant, this increase was predominantly in the insoluble fraction. DM solubilisation
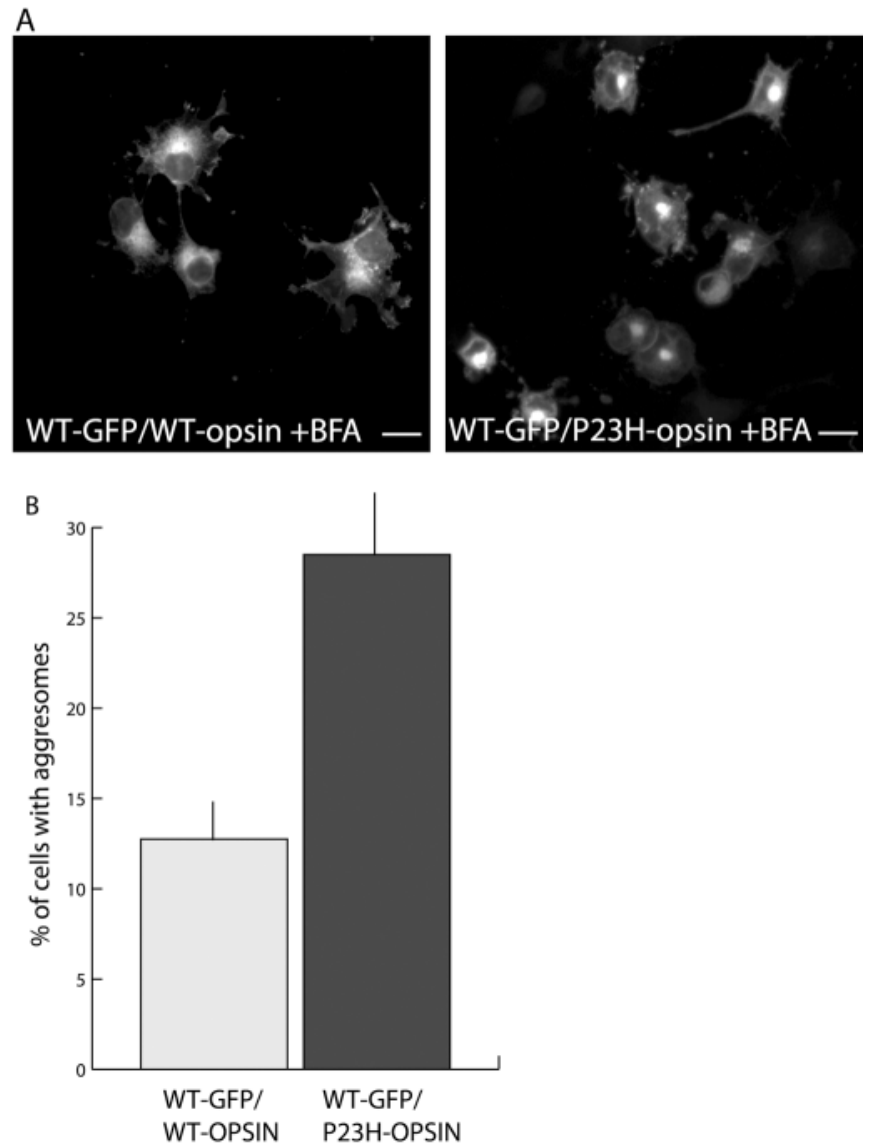

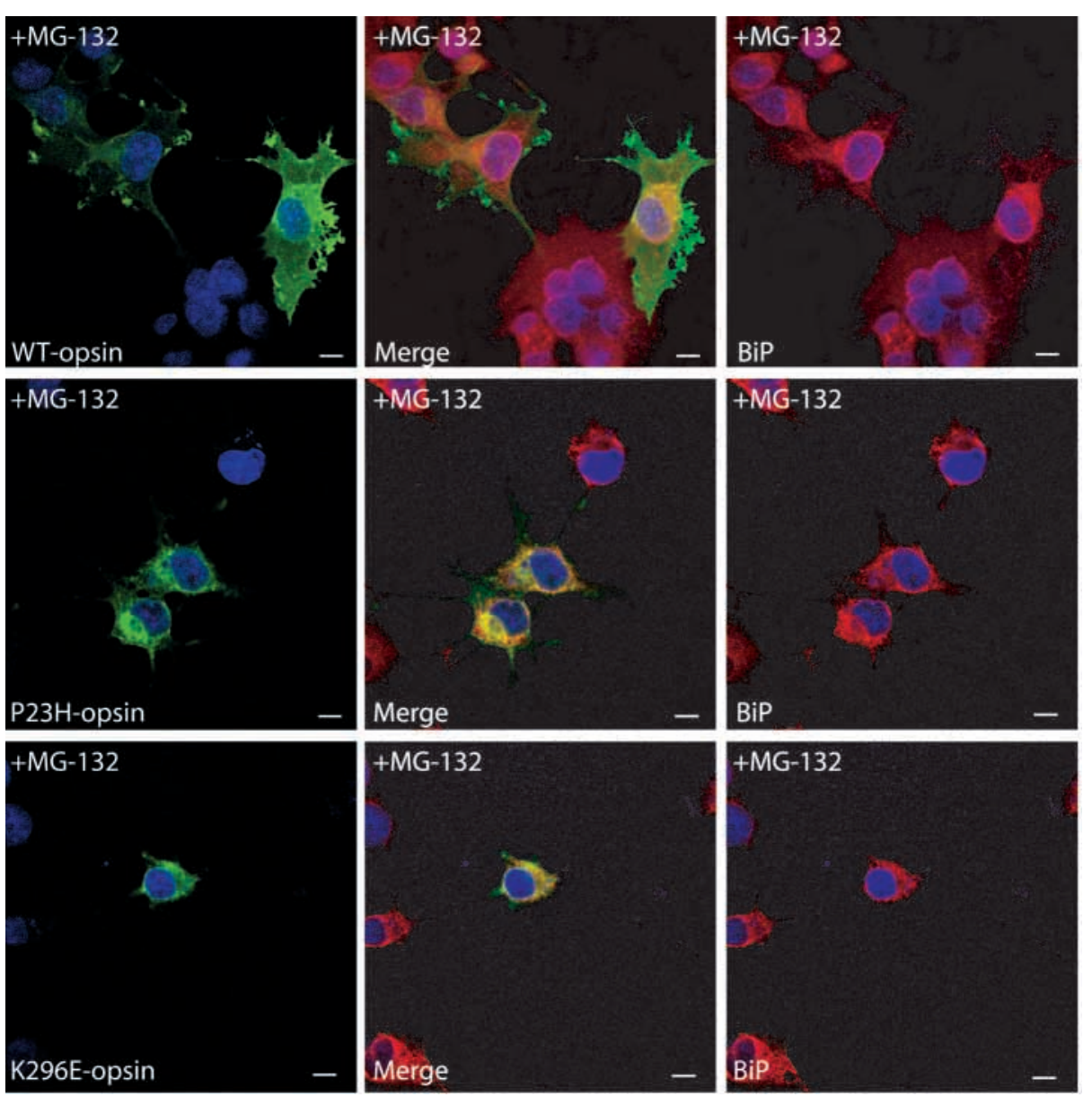

Fig. 6. Inhibition of the proteasome leads to an increase of mutant opsin ER staining. Confocal immunofluorescence shows that inhibition of the proteasome machinery with MG-132 (5 $\mu \mathrm{M}$ for 8 hours) did not affect the processing of WT opsin. The treatment led to an increase in the level of $\mathrm{P} 23 \mathrm{H}$ and K296E mutant opsin in the ER, as shown by colocalisation with the ER-resident Hsp70, BiP. Bar, $10 \mu \mathrm{m}$.

retrotranslocation from the ER. Treatment with MG-132 led to an increase in the Endo-H-sensitive glycoforms of mutant opsin in the DM soluble and DM insoluble fractions (data not shown). In addition to the deglycosylated protein, the insoluble fraction consisted mainly of opsin dimer and high molecular weight species that migrated as a smear that extended to the top of the gel, a feature that is characteristic of ubiquitinated proteins (Ward et al., 1995). This smear may correspond to the variable number of ubiquitin molecules that are added to individual opsin molecules during the process of polyubiquitination, although opsin is prone to self-association and aggregation during SDS-PAGE. The relatively low level of $\mathrm{P} 23 \mathrm{H}$ opsin in the untreated insoluble fraction most probably reflects the insolubility of the opsin aggresomes in the DM-insoluble affords maximal stability for folded opsin but does not simply produce soluble and aggregated fractions. DM solubilisation probably fractionates between folded or nearly folded opsin and opsin folding intermediates, small aggregates and larger aggregates. The major opsin component in the DM-soluble fraction of untreated cells for the wildtype and both mutants corresponded to the mature form of the protein, which is Endo $\mathrm{H}$ insensitive. The major opsin component in the DMinsoluble fraction of untreated cells had the same electrophoretic mobility as PNGase-F-digested opsin, suggesting that it was deglycosylated. Deglycosylation is a hallmark of pellets and their subsequent failure to enter the SDS-PAGE gel. These data suggest that a functioning proteasome is required for the degradation of the mutant opsin by ER-associated degradation (ERAD) and that the proteasome also plays a role in the retrotranslocation of the mutant protein from the ER.

\section{Glycosylation is required for mutant opsin ERAD but not quality control}

We examined the effect of tunicamycin, which blocks the synthesis of precursor oligosaccharides required for N-linked

Fig. 7. Inhibition of the proteasome leads to an increase in mutant opsin. Western blot using mAb 1D4 of opsin in DM-soluble (S) and DM-insoluble (P) protein extracts showed that inhibition of the proteasome machinery with MG-132 (5 $\mu \mathrm{M}$ for 16 hours) (+) led to an increase in the steady state level of mutant opsin in COS-7 cells. The level of WT protein (WT-opsin) was not affected by proteasome inhibition, whereas the level of mutant proteins (P23H-opsin and K296E-opsin) showed a dramatic increase. The electrophoretic mobilities of different glycoforms of opsin were determined empirically using PNGase F and Endo $\mathrm{H}$ : mature ( 40 kDa) (arrowhead); and immature forms (>41 kDa); deglycosylated form $(\sim 30 \mathrm{kDa})(*)$ and

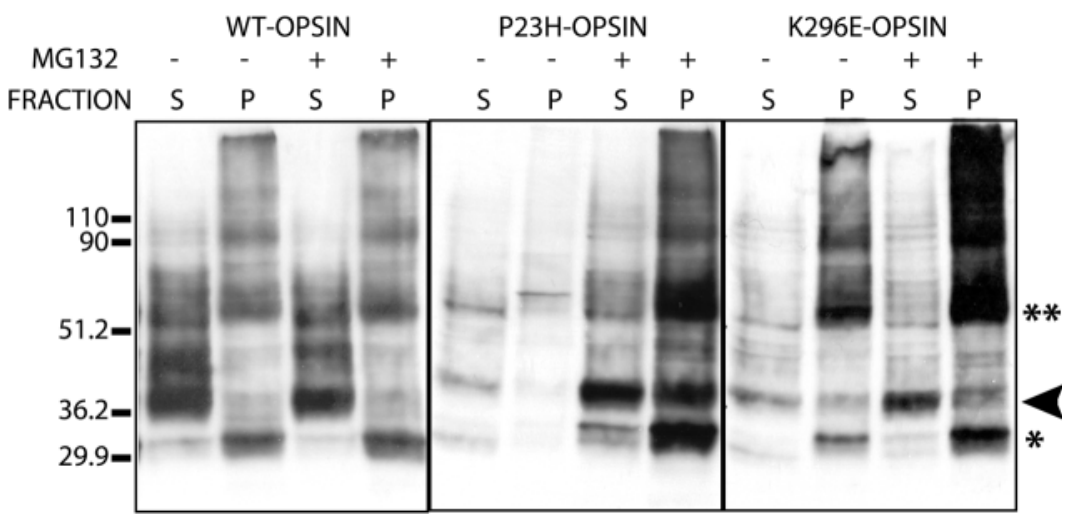
dimer $(\sim 60 \mathrm{kDa})(* *)$. Blot exposures have been adjusted to give equivalent band intensity between WT and mutants, as the WT protein is far more abundant. The positions of the molecular weight markers are indicated on the left in $\mathrm{kDa}$. 

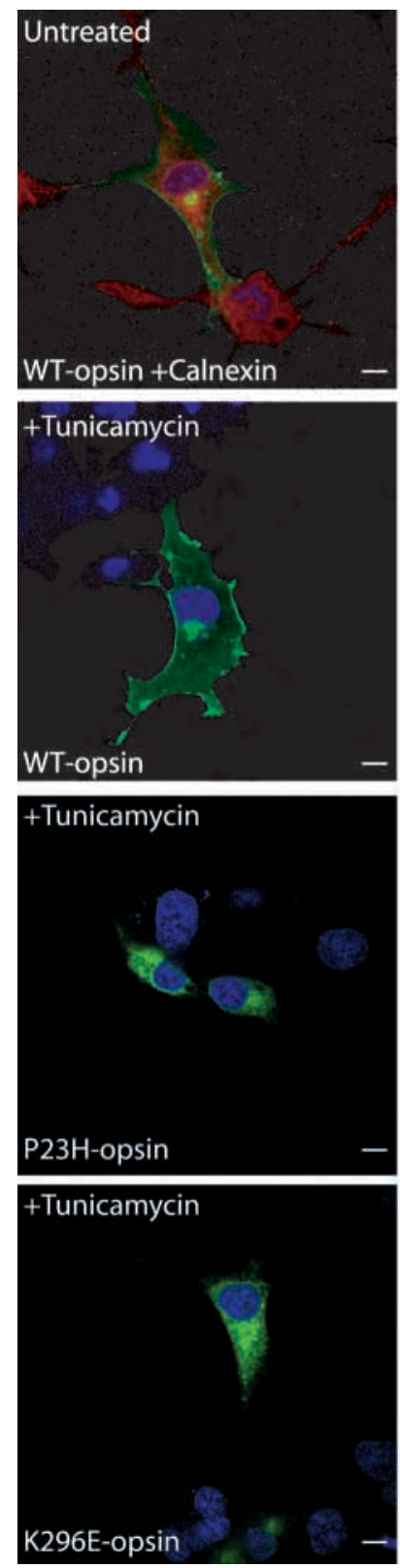
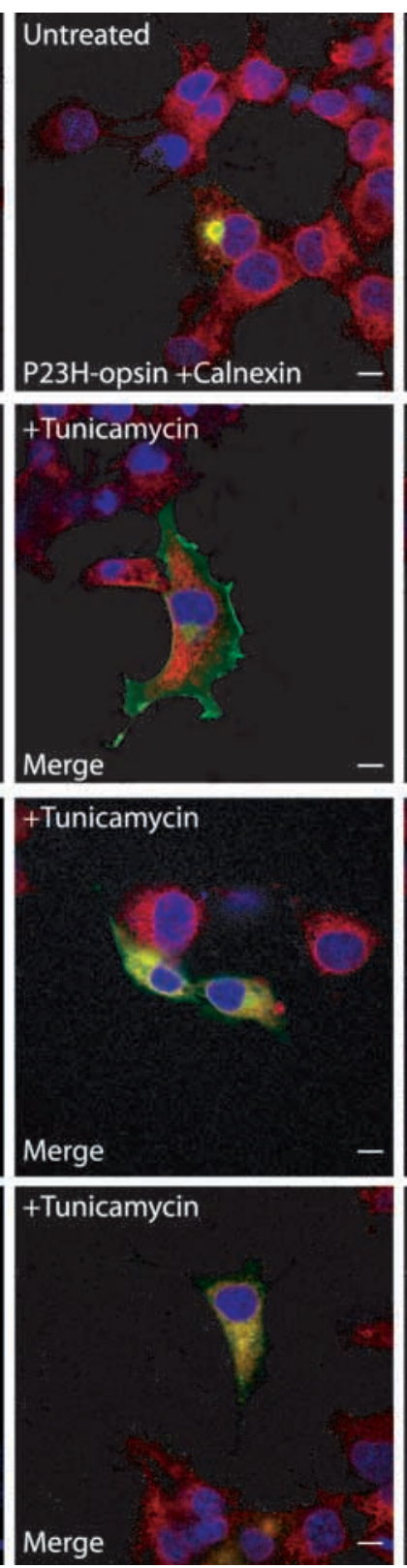
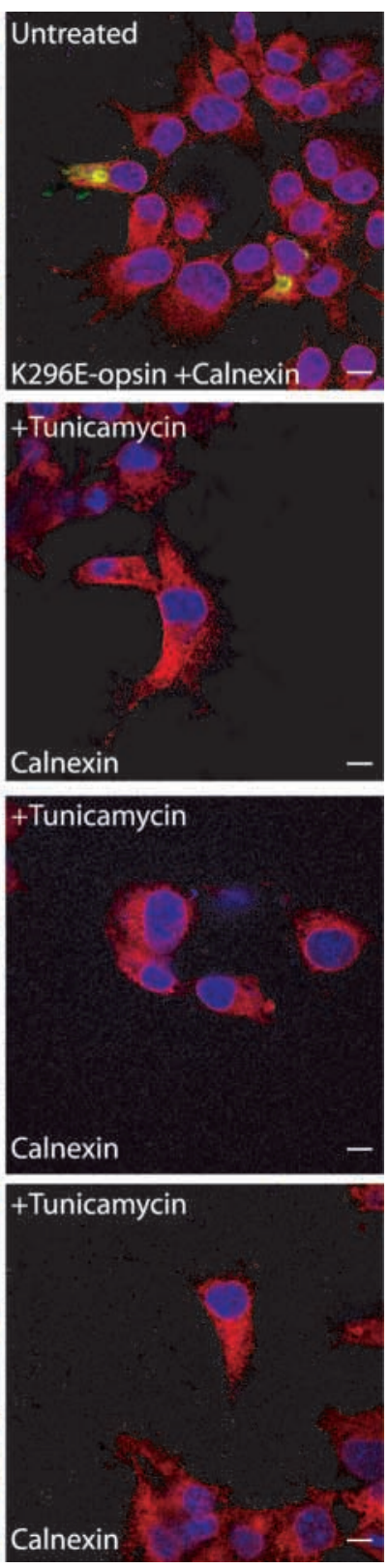

Fig. 8. Inhibition of N-linked glycosylation leads to an increase of mutant opsin ER staining. The colocalisation of WT (WTopsin) and mutant opsins (P23H-opsin and K296E-opsin) with the ER marker calnexin in untreated cells is shown in the top row (Untreated). Inhibition of protein glycosylation with tunicamycin $(0.8 \mu \mathrm{g} / \mathrm{ml}$ for 8 hours) led to an increase in the level of mutant protein retained within the ER. The trafficking of the WT protein (WT-opsin) to the plasma membrane was not affected by the treatment with tunicamycin and showed no increase in ER staining. By contrast, the mutant proteins (P23H-opsin and K296Eopsin) accumulated in the ER as shown by colocalisation with the ER-membranebound lectin chaperone calnexin. Bar, 10 $\mu \mathrm{m}$.

formation of the mature diglycoslyated form of opsin and resulted in the accumulation of non-glycosylated opsin as seen by western blotting (Fig. 9). Although treatment with tunicamycin did not have a major effect on the level of the wild-type protein, the steady state levels of the mutant proteins increased considerably, particularly in the insoluble fraction (data not shown). These observations show that the targeting of mutant opsin for ERAD is dependent on N-linked glycosylation. ER retention of mutant opsin, however, is not affected by tunicamycin and reveals a glycan-independent quality control mechanism that prevents mutant opsin escaping the ER.

\section{9-cis-retinal promotes the targeting of $\mathrm{P} 23 \mathrm{H}$ mutant opsin to the plasma membrane}

Previous studies have suggested that the addition of 11-cis-retinal and 9-cis-

glycosylation, on normal and mutant opsin processing and quality control in vitro. As previously described (Kaushal et al., 1994), tunicamycin did not affect the transport of the wild-type protein to the plasma membrane and did not lead to the retention of the protein within the cell; the small amount of intra-cellular staining observed corresponded to protein trafficking through the Golgi (Fig. 8). The processing of the $\mathrm{P} 23 \mathrm{H}$ and $\mathrm{K} 296 \mathrm{E}$ mutant proteins, in contrast, was dramatically altered by tunicamycin. Similar to the situation with MG-132 treatment, tunicamycin led to an increase in the intensity of ER staining in all cells compared with the untreated cells, as shown by colocalisation with $\mathrm{BiP}$ (data not shown) and calnexin (Fig. 8). The incidence of aggresome formation, however, did not appear to change significantly during either 8 or 14 hours of incubation with tunicamycin.

As expected, treatment with tunicamycin prevented the retinal to mutant-opsin-expressing cells can improve the folding of mutant opsins ( $\mathrm{Li}$ et al., 1998a). Therefore, we examined the effect of 9-cis-retinal on mutant opsin processing and aggresome formation in $\mathrm{P} 23 \mathrm{H}$-opsin-expressing cells. The 9-cis-retinal increased the level of mutant opsin as assessed by western blotting and in particular the mature form of the protein in the soluble fraction, suggesting efficient transit through the Golgi apparatus (Fig. 10). This was confirmed by immunocytochemical analysis of opsin localisation (Fig. 10), as an increase in plasma membrane staining with $\mathrm{P} 23 \mathrm{H}$ could be observed. However, the incubation of 9-cis-retinal did not lead to a significant decrease in the formation of aggresomes over the period of the treatment time. The addition of 9-cisretinal to K296E opsin expressing cells had no effect on the processing of the mutant opsin (data not shown), as would be expected as the mutation has removed the site of retinal attachment. 


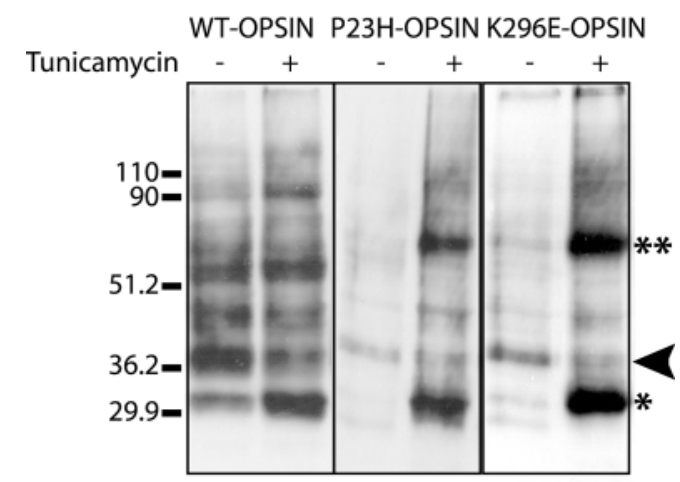

Fig. 9. Inhibition of N-linked glycosylation prevents the degradation of mutant opsin. A western blot using mAb 1D4 of opsin in total protein extracts showed that inhibition of protein glycosylation with tunicamycin $(0.8 \mu \mathrm{g} / \mathrm{ml}$ for 16 hours) led to an increase in the steady state level of mutant protein. The level of total WT opsin was not noticeably altered, whereas the level of mutant (P23H-opsin and K296E-opsin) increased significantly after treatment. The electrophoretic mobilities of different glycoforms of opsin were determined empirically using PNGase F and Endo H: mature ( 40 $\mathrm{kDa})$ (arrowhead); and immature forms ( $>41 \mathrm{kDa})$; deglycosylated form $(\sim 30 \mathrm{kDa})(*)$ and dimer $(\sim 60 \mathrm{kDa})(* *)$. Blot exposures have been adjusted to give equivalent band intensity between WT and mutants. The positions of the molecular weight markers are indicated on the left in $\mathrm{kDa}$.

\section{Discussion}

Mutations in the rod visual pigment rhodopsin are the major cause of inherited retinal degeneration, and the majority of these mutations lead to the misfolding of the protein. Misfolded opsin is degraded by the ubiquitin-proteasome system in COS-7 cells and in SH-SY5Y neuroblastoma cells (R.S.S. and M.E.C., unpublished observations). This degradation requires the retrotranslocation of the protein from the ER and is dependent on the presence of an $\mathrm{N}$-linked glycosylation 'tag' and a functional proteasome. The retrotranslocated mutant opsin appears to be degraded less efficiently than mutant CFTR, despite their expression levels being similar. Mutant rhodopsin, therefore, forms aggresomes spontaneously in COS-7 cells, in contrast to CFTR, where the majority of the mutant protein is rapidly degraded and inhibition of the proteasome is required to stimulate aggresome formation (Johnston et al., 1998). The addition of a GFP tag to the C-terminus of opsin increases the rate of aggresome formation. This would agree with an earlier study of opsin-GFP that showed that although the protein can fold normally and produce functional visual pigment, the misfolding rate is higher than non-tagged protein (Moritz et al., 2001). Furthermore, in the presence of mutant protein aggresomes, the normal wild-type protein can be recruited to the inclusions.

The correct folding of rhodopsin appears to be exquisitely sensitive to changes in the primary amino acid sequence, as judged by the large number of single amino acid substitutions that lead to ADRP (OMIM: http://www.ncbi.nlm.nih.gov/ entrez/dispomim.cgi?id=180380). At present, the reasons for this sensitivity are not clear even though the structure of rhodopsin has been solved (Palczewski et al., 2000), but may relate to the hydrophobicity of the seven transmembrane domains and the need for their membrane insertion, coupled to
A
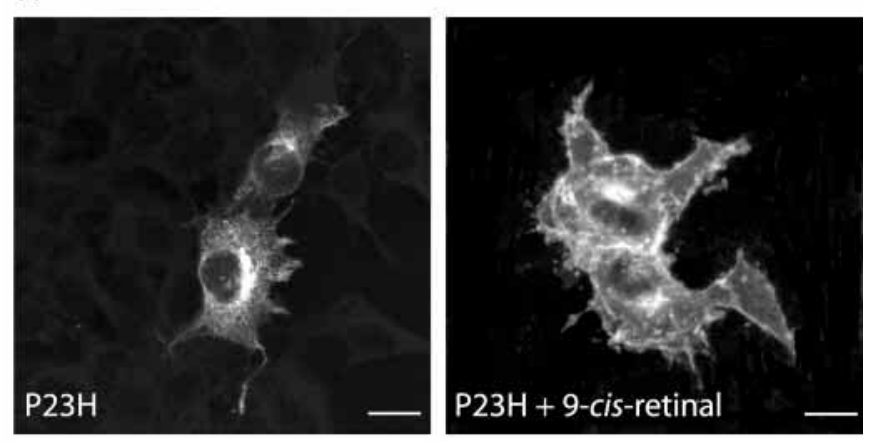

B

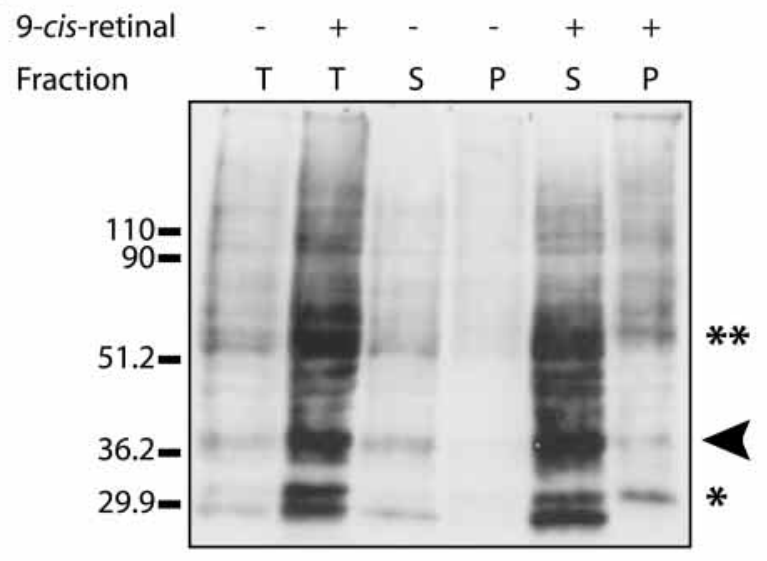

Fig. 10. Treatment with 9-cis-retinal leads to an increase in soluble mutant opsin that reaches the plasma membrane. (A) Confocal immunofluorescence showing that overnight treatment of COS-7 cells expressing $\mathrm{P} 23 \mathrm{H}$-opsin leads to an increase in the amount of protein that reaches the plasma membrane. Bar, $10 \mu \mathrm{m}$. (B) A western blot using mAb 1D4 of P23H-opsin in total (T), DM-soluble $(\mathrm{S})$ and DM-insoluble $(\mathrm{P})$ protein extracts shows that the addition of 9-cis-retinal (+) dramatically increases the amount of opsin in the cells and that most of this is in the soluble fraction. The electrophoretic mobilities of different glycoforms of opsin are indicated: mature ( $40 \mathrm{kDa})$ (arrowhead); and immature forms (>41 $\mathrm{kDa})$; deglycosylated form $(\sim 30 \mathrm{kDa})(*)$ and dimer $(\sim 60 \mathrm{kDa})(* *)$. The positions of the molecular weight markers are indicated on the left in $\mathrm{kDa}$.

their arrangement in the fully folded protein. It is also possible that folding of the protein is subjected to particularly tight quality control in order to prevent the incorporation of improperly folded protein into the outer segment, as this could lead to an unacceptable level of 'noise' through constitutive activity.

Glycoslyation plays pivotal roles in protein folding, oligomerisation, quality control, sorting and transport (Helenius and Aebi, 2001). Rhodopsin is glycosylated at asparagine residues 2 and 15 in the ER, and the glycan groups are modified in the Golgi on the way to the outer segment in photoreceptors or the plasma membrane in COS-7 cells. The importance of glycosylation in the folding and the processing of opsin has been studied extensively but has generated apparently conflicting data. Inhibition of glycoslyation with tunicamycin, which blocks the synthesis of precursor oligosaccharides required for $\mathrm{N}$-linked glycoslyation, has been 
used to study rhodopsin biogenesis in vivo and in vitro. Treatment of isolated Xenopus laevis and Rana pipiens retinas with tunicamycin disrupts normal outer segment disc assembly but has no effect on the intracellular transport of rhodopsin (Fliesler et al., 1985; Fliesler and Basinger, 1985). Similarly, tunicamycin does not prevent the transport of rhodopsin to the plasma membrane in cell culture (Kaushal et al., 1994), and deglycosylated rhodopsin retains its spectral properties (Kaushal et al., 1994; Prasad et al., 1992). By contrast, sitedirected mutagenesis of the asparagine residues required for $\mathrm{N}$ linked glycosylation leads to the accumulation of Drosophila rhodopsin (Rh1) protein within the ER and retinal degeneration (Katanosaka et al., 1998; O'Tousa, 1992; Webel et al., 2000). However, such changes in the primary amino acid sequence may also disrupt protein folding and lead to the protein being retained within the ER because of misfolding, as seen with mutations in the tri-peptide consensus sequence for $\mathrm{N}$-linked glycosylation in bovine opsin (Kaushal et al., 1994). Our data show that the major effect of inhibiting N-linked glycosylation in COS-7 cells is to prevent the degradation of the mutant protein and lead to its retention in the ER, whereas glycosylation does not appear to be required for the folding and transport of the normal protein. These results are consistent with the major role of N-linked glycosylation of rhodopsin in the early secretory pathway being the quality control and degradation of misfolded protein. The glycan moieties of rhodopsin may be required for the recognition of misfolded opsin by ER-resident lectin chaperones involved in ERAD, such as calnexin and calreticulin (Helenius and Aebi, 2001), or the recently discovered ER degradation enhancing $\alpha$ mannosidase-like protein, EDEM (Hosokawa et al., 2001). It appears, however, that the N-linked glycan moieties of rhodopsin are not required for the non-glycosylated protein to be recognised as misfolded as the mutant protein is retained within the ER and prevented from exiting to the Golgi. Therefore, the quality control of opsin folding is not dependent on the recognition of the misfolded protein by ER-resident lectin chaperones, such as calnexin and calreticulin, but may involve other chaperones such as BiP and Grp94, which have previously been shown to bind mutant opsins (Anukanth and Khorana, 1994). The major role of rhodopsin glycosylation in the early secretory pathway appears to be the facilitation of misfolded protein degradation. Later in the secretory pathway, however, N-linked glycosylation may play other pivotal roles in post-Golgi protein sorting, targeting to the rod outer segment, disk assembly (Fliesler et al., 1985; Fliesler and Basinger, 1985) or even phototransduction (Kaushal et al., 1994).

The misfolded opsin is recognised and bound by the ERADassociated lectins, then the protein is destined for retrotranslocation and degradation by the proteasome. Both luminal and transmembrane proteins retained in the ER are now known to be retrotranslocated into the cytosol in a process that involves ER chaperones and components of the protein import machinery (Plemper and Wolf, 1999). Once exposed to the cytosolic milieu, retrotranslocated proteins are degraded by the proteasome, in most cases following polyubiquitination. There is growing evidence that both the ubiquitin-conjugating machinery and proteasomes may be associated with the cytosolic face of the ER membrane and that they could be functionally coupled to the process of retrotranslocation
(Hirsch and Ploegh, 2000). In the case of CFTR, inhibition of the proteasome does not inhibit retrotranslocation but instead stimulates aggresome formation by increasing the amount of undegraded misfolded CFTR in the cytosol (Johnston et al., 1998). By contrast, inhibition of the proteasome appears to increase the amount of mutant opsin that is retained within the ER, suggesting that the retrotranslocation of mutant opsin is coupled to the function of the proteasome, as has been described for several other proteins (Chillaron and Haas, 2000; Mancini et al., 2000; Mayer et al., 1998). Another difference between mutant opsin and CFTR is the efficiency of degradation of the misfolded protein. $\triangle$ F508CFTR is degraded very effectively by the proteasome, and it is only on proteasome inhibition that the mutant protein aggresomes are readily seen in all cells expressing the mutant protein. Mutant opsin does not appear to be efficiently degraded by the proteasome and forms aggresomes spontaneously in the absence of proteasome inhibition. The incidence of aggresome formation varies between mutations and most probably reflects the rate that the proteins achieve a native or quasi-native state and their misfolding rate.

Li et al. demonstrated that the addition of 11-cis-retinal and 9-cis-retinal to mutant-opsin-expressing cells could improve the folding of T17M mutant opsin but not a mutation in the Cterminus of the opsin ( $\mathrm{Li}$ et al., 1998a). Incubation of $\mathrm{P} 23 \mathrm{H}-$ expressing cells with 9-cis-retinal increased the level of the mature form of the protein in the soluble fraction, suggesting efficient transit through the Golgi apparatus, and this correlated with an increase in plasma membrane staining. However, the incubation with 9-cis-retinal overnight did not lead to a significant decrease in the formation of aggresomes during the treatment time. These data suggest that, although the ligand can be used to promote mutant opsin folding and prevent its degradation, once an opsin aggresome has formed treatment with ligand cannot disaggregate it.

The burden of degrading opsin could weigh heavily on a rod photoreceptor cell. Normally, the outer segment and the vast quantities of rhodopsin that it contains are degraded by the retinal pigment epithelium (RPE). Given that opsin corresponds to at least $30 \%$ of the protein produced by a rod cell, even if only a small percentage of this misfolded and needed to be degraded it could represent a significant problem for the ER-resident chaperones that perform the quality control and ERAD, as well as the ubiquitin-proteasome machinery. This could compromise the normal biosynthetic activity of secretory pathway in the inner segment and lead to the shortening of outer segments that has been observed in animal models with the P23H mutation (Machida et al., 2000). The rate of mutant opsin misfolding would determine the effect on normal protein biosynthesis and thereby outer segment length. The presence of mutant protein also appears to affect the processing of the normal protein (Colley et al., 1995; Wu et al., 1998), and dominant mutations in the rhodopsin gene, Nina-E, of Drosophila exert a dominant-negative effect on the biosynthesis of the normal rhodopsin protein (Colley et al., 1995; Kurada and O'Tousa, 1995). Our data show that mutant opsin aggresomes can recruit the normal protein. It may be that the smaller aggregates of mutant protein that are the precursors of aggresomes and are destined for degradation also recruit the wild-type protein, leading to the degradation of the normal protein. In photoreceptors in vivo, opsin aggresomes may form 
only rarely as the photoreceptor has a protein folding machinery that is finely tuned for opsin synthesis, including specialised chaperones (Chapple et al., 2001). Aggregates of electron-dense rhodopsin have been observed in both human ADRP and animal models of rhodopsin ADRP (Bunt-Milam et al., 1983; Li et al., 1998b), suggesting their potential importance to the disease process. The formation of opsin aggresomes, however, in human and animal models of RP remains to proven. We propose that aggresome formation could occur as a stochastic event with a frequency that is inversely proportional to the mutant protein's ability to fold correctly. This 'risk' could in turn be further modified by cellular stress, which would compromise the cellular chaperone machinery and could explain the apparent 'one-hit' nature of photoreceptor cell death in rhodopsin RP (Clarke et al., 2001). The formation of an aggresome within a photoreceptor could lead rapidly to the death of the photoreceptor, as opposed to its dysfunction.

The formation of opsin aggresomes may have important consequences for photoreceptor viability. The presence of protein aggregates has been shown to compromise the ubiquitinproteasome machinery (Bence et al., 2001), and this could be detrimental to several cellular pathways. Similarly, the disruption of the cytoskeleton could alter intracellular protein and organelle transport. The recruitment of cellular chaperones to the protein aggregates could expose the cells to environmental stress and may stimulate an unfolded protein response, which could lead to the downstream activation of caspases (Nakagawa et al., 2000). We have shown that mutant opsin aggregates can recruit the normal protein, and it is possible that the aggregates recruit other proteins. A recent study has shown that opsin aggregates appear to be specific, and although they colocalise with other protein aggregates, such as CFTR and TCR $\alpha$ subunits, they do not co-aggregate (Rajan et al., 2001). Nevertheless, the recruitment of specific opsin-binding proteins [e.g. Tctex (Tai et al., 1999) and other C-termini-binding sorting factors (Tam et al., 2000) or phototransduction components] to opsin aggresomes could also influence the targeting of the normal protein to the outer segment and compromise photoreceptor viability. Cell-culture-based systems will be of value in determining some of the consequences of opsin misfolding and aggresome formation and how these events can be manipulated. It is vital, however, to determine the fate of misfolded opsin in photoreceptors in vivo and determine the precise cellular consequences for photoreceptors of rhodopsin misfolding in order to develop novel therapies for ADRP.

We are grateful to the following for providing reagents: D. Oprian for wild-type and K296E rhodopsin in pMT3; R. Molday, L. Molday and the National Cell Culture Centre for rhodopsin mAbs 1D4 and 4D2; Hans-Peter Hauri for anti-ERGIC-53; and R. Kopito for $\Delta$ F508 CFTR-GFP and c-myc-ubiquitin plasmids (Ward et al., 1995). This work is supported by the EC.

\section{References}

Alves-Rodrigues, A., Gregori, L. and Figueiredo-Pereira, M. E. (1998). Ubiquitin, cellular inclusions and their role in neurodegeneration. Trends Neurosci. 21, 516-520.

Anukanth, A. and Khorana, H. G. (1994). Structure and function in rhodopsin. Requirements of a specific structure for the intradiscal domain. J. Biol. Chem. 269, 19738-19744.

Bence, N. F., Sampat, R. M. and Kopito, R. R. (2001). Impairment of the ubiquitin-proteasome system by protein aggregation. Science 292, 15521555.

Bunt-Milam, A. H., Kalina, R. E. and Pagon, R. A. (1983). Clinicalultrastructural study of a retinal dystrophy. Invest. Ophthalmol. Vis. Sci. 24, 458-469.

Chapple, J. P., Grayson, C., Hardcastle, A. J., Saliba, R. S., van der Spuy, J. and Cheetham, M. E. (2001). Unfolding retinal dystrophies: a role for molecular chaperones? Trends Mol. Med. 7, 414-421.

Chapple, J. P., Hardcastle, A. J., Grayson, C., Spackman, L. A., Willison, K. R. and Cheetham, M. E. (2000). Mutations in the N-terminus of the Xlinked retinitis pigmentosa protein RP2 interfere with the normal targeting of the protein to the plasma membrane. Hum. Mol. Genet. 9, 1919-1926.

Chillaron, J. and Haas, I. G. (2000). Dissociation from BiP and retrotranslocation of unassembled immunoglobulin light chains are tightly coupled to proteasome activity. Mol. Biol. Cell, 11, 217-226.

Clarke, G., Lumsden, C. J. and McInnes, R. R. (2001). Inherited neurodegenerative diseases: the one-hit model of neurodegeneration. Hum. Mol. Genet. 10, 2269-2275.

Colley, N. J., Cassill, J. A., Baker, E. K. and Zuker, C. S. (1995). Defective intracellular transport is the molecular basis of rhodopsin- dependent dominant retinal degeneration. Proc. Natl. Acad. Sci. USA 92, 3070-3074.

Dryja, T. P., McGee, T. L., Reichel, E., Hahn, L. B., Cowley, G. S., Yandell, D. W., Sandberg, M. A. and Berson, E. L. (1990). A point mutation of the rhodopsin gene in one form of retinitis pigmentosa. Nature 343, 364366.

Fliesler, S. J. and Basinger, S. F. (1985). Tunicamycin blocks the incorporation of opsin into retinal rod outer segment membranes. Proc. Natl. Acad. Sci. USA 82, 1116-1120.

Fliesler, S. J., Rayborn, M. E. and Hollyfield, J. G. (1985). Membrane morphogenesis in retinal rod outer segments: inhibition by tunicamycin. $J$. Cell Biol. 100, 574-587.

Garcia-Mata, R., Bebok, Z., Sorscher, E. J. and Sztul, E. S. (1999). Characterization and dynamics of aggresome formation by a cytosolic GFPchimera. J. Cell Biol. 146, 1239-1254.

Heath, C. M., Windsor, M. and Wileman, T. (2001). Aggresomes resemble sites specialized for virus assembly. J. Cell Biol. 153, 449-455.

Helenius, A. and Aebi, M. (2001). Intracellular functions of N-linked glycans. Science 291, 2364-2369.

Hirsch, C. and Ploegh, H. L. (2000). Intracellular targeting of the proteasome. Trends Cell Biol. 10, 268-272.

Hosokawa, N., Wada, I., Hasegawa, K., Yorihuzi, T., Tremblay, L. O., Herscovics, A. and Nagata, K. (2001). A novel ER alpha-mannosidaselike protein accelerates ER-associated degradation. EMBO Rep. 2, 415-422.

Humphries, M. M., Rancourt, D., Farrar, G. J., Kenna, P., Hazel, M., Bush, R. A., Sieving, P. A., Sheils, D. M., McNally, N., Creighton, P. et al. (1997). Retinopathy induced in mice by targeted disruption of the rhodopsin gene. Nat. Genet. 15, 216-219.

Johnston, J. A., Dalton, M. J., Gurney, M. E. and Kopito, R. R. (2000). Formation of high molecular weight complexes of mutant $\mathrm{Cu}, \mathrm{Zn}$ superoxide dismutase in a mouse model for familial amyotrophic lateral sclerosis. Proc. Natl. Acad. Sci. USA 97, 12571-12576.

Johnston, J. A., Ward, C. L. and Kopito, R. R. (1998). Aggresomes: a cellular response to misfolded proteins. J. Cell Biol. 143, 1883-1898.

Katanosaka, K., Tokunaga, F., Kawamura, S. and Ozaki, K. (1998). Nlinked glycosylation of Drosophila rhodopsin occurs exclusively in the amino-terminal domain and functions in rhodopsin maturation. FEBS Lett. 424, 149-154.

Kaushal, S. and Khorana, H. G. (1994). Structure and function in rhodopsin. 7. Point mutations associated with autosomal dominant retinitis pigmentosa. Biochemistry 33, 6121-6128.

Kaushal, S., Ridge, K. D. and Khorana, H. G. (1994). Structure and function in rhodopsin: the role of asparagine-linked glycosylation. Proc. Natl. Acad. Sci. USA 91, 4024-4028.

Kaytor, M. D. and Warren, S. T. (1999). Aberrant protein deposition and neurological disease. J. Biol. Chem. 274, 37507-37510.

Kopito, R. R. (2000). Aggresomes, inclusion bodies and protein aggregation. Trends Cell Biol. 10, 524-530.

Kurada, P. and O'Tousa, J. E. (1995). Retinal degeneration caused by dominant rhodopsin mutations in Drosophila. Neuron 14, 571-579.

Li, T., Sandberg, M. A., Pawlyk, B. S., Rosner, B., Hayes, K. C., Dryja, T. P. and Berson, E. L. (1998a). Effect of vitamin A supplementation on rhodopsin mutants threonine-17 $\rightarrow$ methionine and proline- $347 \rightarrow$ serine in transgenic mice and in cell cultures. Proc. Natl. Acad. Sci. USA 95, 1193311938. 
Li, Z. Y., Wong, F., Chang, J. H., Possin, D. E., Hao, Y., Petters, R. M. and Milam, A. H. (1998b). Rhodopsin transgenic pigs as a model for human retinitis pigmentosa. Invest. Ophthalmol. Vis. Sci. 39, 808-819.

Machida, S., Kondo, M., Jamison, J. A., Khan, N. W., Kononen, L. T., Sugawara, T., Bush, R. A. and Sieving, P. A. (2000). P23H rhodopsin transgenic rat: correlation of retinal function with histopathology. Invest. Ophthalmol. Vis. Sci. 41, 3200-3209.

Mancini, R., Fagioli, C., Fra, A. M., Maggioni, C. and Sitia, R. (2000). Degradation of unassembled soluble Ig subunits by cytosolic proteasomes: evidence that retrotranslocation and degradation are coupled events. FASEB J. 14, 769-778.

Mayer, T. U., Braun, T. and Jentsch, S. (1998). Role of the proteasome in membrane extraction of a short-lived ER-transmembrane protein. EMBO J. 17, 3251-3257.

Moritz, O. L., Tam, B. M., Papermaster, D. S. and Nakayama, T. (2001). A functional rhodopsin-green fluorescent protein fusion protein localizes correctly in transgenic Xenopus laevis retinal rods and is expressed in a timedependent pattern. J. Biol. Chem. 276, 28242-28251.

Nakagawa, T., Zhu, H., Morishima, N., Li, E., Xu, J., Yankner, B. A. and Yuan, J. (2000). Caspase-12 mediates endoplasmic-reticulum-specific apoptosis and cytotoxicity by amyloid-beta. Nature 403, 98-103.

O'Tousa, J. E. (1992). Requirement of N-linked glycosylation site in Drosophila rhodopsin. Vis. Neurosci. 8, 385-390.

Olsson, J. E., Gordon, J. W., Pawlyk, B. S., Roof, D., Hayes, A., Molday, R. S., Mukai, S., Cowley, G. S., Berson, E. L. and Dryja, T. P. (1992). Transgenic mice with a rhodopsin mutation (Pro23His): a mouse model of autosomal dominant retinitis pigmentosa. Neuron 9, 815-830.

Palczewski, K., Kumasaka, T., Hori, T., Behnke, C. A., Motoshima, H., Fox, B. A., Le Trong, I., Teller, D. C., Okada, T., Stenkamp, R. E. et al. (2000). Crystal structure of rhodopsin: A G protein-coupled receptor. Science 289, 739-745.

Plemper, R. K. and Wolf, D. H. (1999). Retrograde protein translocation: ERADication of secretory proteins in health and disease. Trends Biochem. Sci. 24, 266-270.

Portera Cailliau, C., Sung, C. H., Nathans, J. and Adler, R. (1994). Apoptotic photoreceptor cell death in mouse models of retinitis pigmentosa. Proc. Natl. Acad. Sci. USA 91, 974-978.

Prasad, A. V., Plantner, J. J. and Kean, E. L. (1992). Effect of enzymatic deglycosylation on the regenerability of bovine rhodopsin. Exp. Eye Res. 54, 913-920.

Rajan, R. S., Illing, M. E., Bence, N. F. and Kopito, R. R. (2001). Specificity in intracellular protein aggregation and inclusion body formation. Proc. Natl. Acad. Sci. USA 98, 13060-13065.

Roof, D. J., Adamian, M. and Hayes, A. (1994). Rhodopsin accumulation at abnormal sites in retinas of mice with a human $\mathrm{P} 23 \mathrm{H}$ rhodopsin transgene. Invest. Ophthalmol. Vis. Sci. 35, 4049-4062.

Sherman, M. Y. and Goldberg, A. L. (2001). Cellular defenses against unfolded proteins: a cell biologist thinks about neurodegenerative diseases. Neuron 29, 15-32.

Sung, C. H., Schneider, B. G., Agarwal, N., Papermaster, D. S. and Nathans, J. (1991). Functional heterogeneity of mutant rhodopsins responsible for autosomal dominant retinitis pigmentosa. Proc. Natl. Acad. Sci. USA 88, 8840-8844.

Sung, C. H., Davenport, C. M. and Nathans, J. (1993). Rhodopsin mutations responsible for autosomal dominant retinitis pigmentosa. Clustering of functional classes along the polypeptide chain. J. Biol. Chem. 268, 2664526649.

Sung, C. H., Makino, C., Baylor, D. and Nathans, J. (1994). A rhodopsin gene mutation responsible for autosomal dominant retinitis pigmentosa results in a protein that is defective in localization to the photoreceptor outer segment. J. Neurosci. 14, 5818-5833.

Tai, A. W., Chuang, J. Z., Bode, C., Wolfrum, U. and Sung, C. H. (1999). Rhodopsin's carboxy-terminal cytoplasmic tail acts as a membrane receptor for cytoplasmic dynein by binding to the dynein light chain Tctex-1. Cell 97, 877-887.

Tam, B. M., Moritz, O. L., Hurd, L. B. and Papermaster, D. S. (2000). Identification of an outer segment targeting signal in the $\mathrm{COOH}$ terminus of rhodopsin using transgenic Xenopus laevis. J. Cell Biol. 151, 13691380.

Waelter, S., Boeddrich, A., Lurz, R., Scherzinger, E., Lueder, G., Lehrach, H. and Wanker, E. E. (2001). Accumulation of mutant huntingtin fragments in aggresome-like inclusion bodies as a result of insufficient protein degradation. Mol. Biol. Cell 12, 1393-1407.

Ward, C. L., Omura, S. and Kopito, R. R. (1995). Degradation of CFTR by the ubiquitin-proteasome pathway. Cell 83, 121-127.

Webel, R., Menon, I., O'Tousa, J. E. and Colley, N. J. (2000). Role of asparagine-linked oligosaccharides in rhodopsin maturation and association with its molecular chaperone, NinaA. J. Biol. Chem. 275, 24752-24759.

Wu, T. H., Ting, T. D., Okajima, T. I., Pepperberg, D. R., Ho, Y. K., Ripps, H. and Naash, M. I. (1998). Opsin localization and rhodopsin photochemistry in a transgenic mouse model of retinitis pigmentosa. Neuroscience 87, 709-717. 